\title{
Diabetic Retinopathy: Two Faces of the Same Coin
}
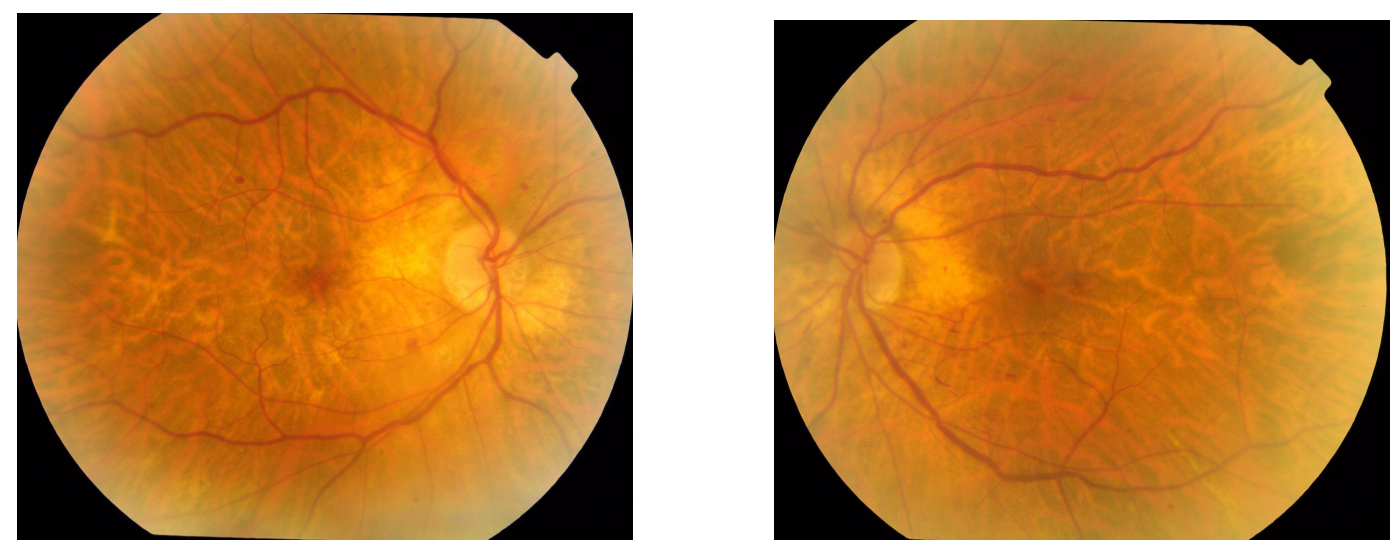

FIGURES 1 (left) and 2 (right). Case A. Engorgement of retinal veins and prominent arteriovenous nicking at the inferior temporal arcade in the left eye. There are multiple, small round intraretinal hemorrhages in both eyes as well as superficial flame-shaped hemorrhages in the left eye.

Silvia Muñoz*, Silvia Sanz, and Núria Planas

Hospital Universitari de Bellvitge, Ophthalmology Department, L'Hospitalet de Llobregat, Barcelona, Spain

E-mail: smq@ya.com

Received September 29, 2008; Revised October 3, 2008; Accepted October 5, 2008; Published November 22, 2008

We report two contrasting cases of diabetic retinopathy to illustrate vascular and retinal abnormalities in this condition. In the first case, mild diabetic retinopathy is diagnosed in an asymptomatic patient with diabetes mellitus of recent onset. The second patient has severe diabetic retinopathy, causing vision loss as a consequence of poor metabolic control.

KEYWORDS: nonproliferative diabetic retinopathy, proliferative diabetic retinopathy, neovascular glaucoma, retinal hemorrhages, retinal new vessels

\section{CASE A}

A 59-year-old woman was diagnosed with diabetes mellitus during an admission for urinary sepsis. She used lenses for high myopia. Best corrected visual acuity was 20/30 in the right eye (RE) and 20/40 in the 
left eye (LE). Anterior segment examination revealed bilateral nuclear cataracts. Fundus examination showed moderate nonproliferative diabetic retinopathy in both eyes (Figs. 1 and 2).

\section{CASE B}

A 60-year-old woman with longstanding type-2 diabetes mellitus with poor metabolic control, hypertension, and mild renal insufficiency presented with pain and blurred vision in the RE. Fundus examination revealed multiple vascular and retinal abnormalities in the LE (Fig. 3). The lack of clear media in the RE did not allow proper examination, so eye ultrasonography was performed and showed signs of retinal traction. On the basis of these findings, severe proliferative diabetic retinopathy was diagnosed in the LE and neovascular glaucoma was diagnosed in the RE.

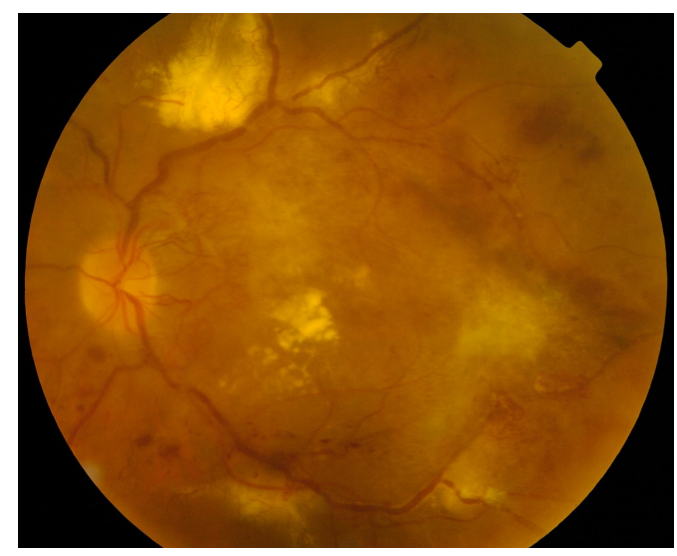

FIGURE 3. Case B. Retinal changes in the LE include extensive lipid exudate deposition in the macular area and superior temporal arcade, dot and blot intraretinal hemorrhages, and deep, shapeless subretinal hemorrhages. There is also marked venous beading and multiple new vessels around the optic nerve and both temporal arcades. Macular retina is thickened, suggesting the presence of macular edema.

\section{REFERENCES}

1. Wilkinson, C.P., Ferris, F.L., Klein, R.E., et al. (2003) Proposed international clinical diabetic retinopathy and diabetic macular edema disease severity scales. Ophthalmology 110, 1677-1682.

2. Morello, C.M. (2007) Etiology and natural history of diabetic retinopathy: an overview. Am. J. Health Syst. Pharm. 64(Suppl 12), S3-7.

3. Liew, G. and Wang, J.J. (2007) Retinal vascular signs in diabetes and hypertension- review. Arq. Bras. Endocrinol. Metab. 51(2), 352-362.

\section{This article should be cited as follows:}

Muñoz, S., Sanz, S., and Planas, N. (2008) Diabetic retinopathy: two faces of the same coin. TheScientificWorldJOURNAL 8, 1152-1153. DOI 10.1100/tsw.2008.138. 


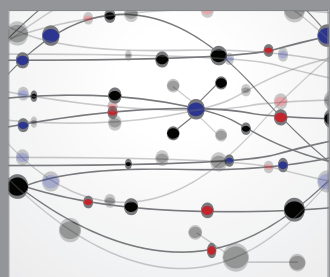

The Scientific World Journal
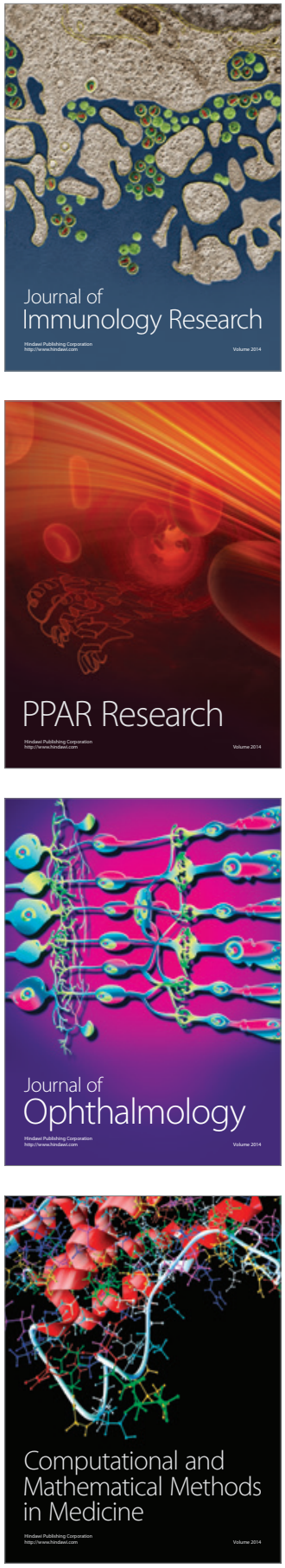

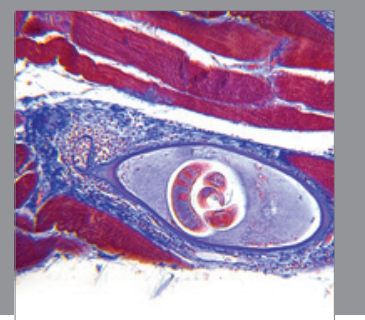

Gastroenterology

Research and Practice
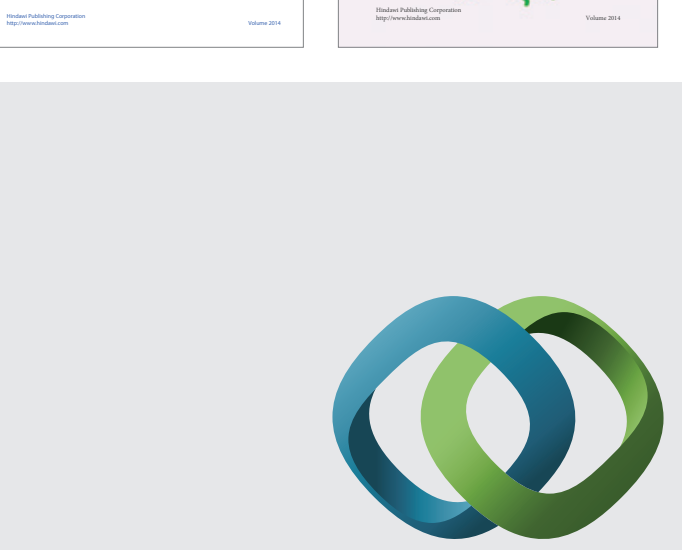

\section{Hindawi}

Submit your manuscripts at

http://www.hindawi.com
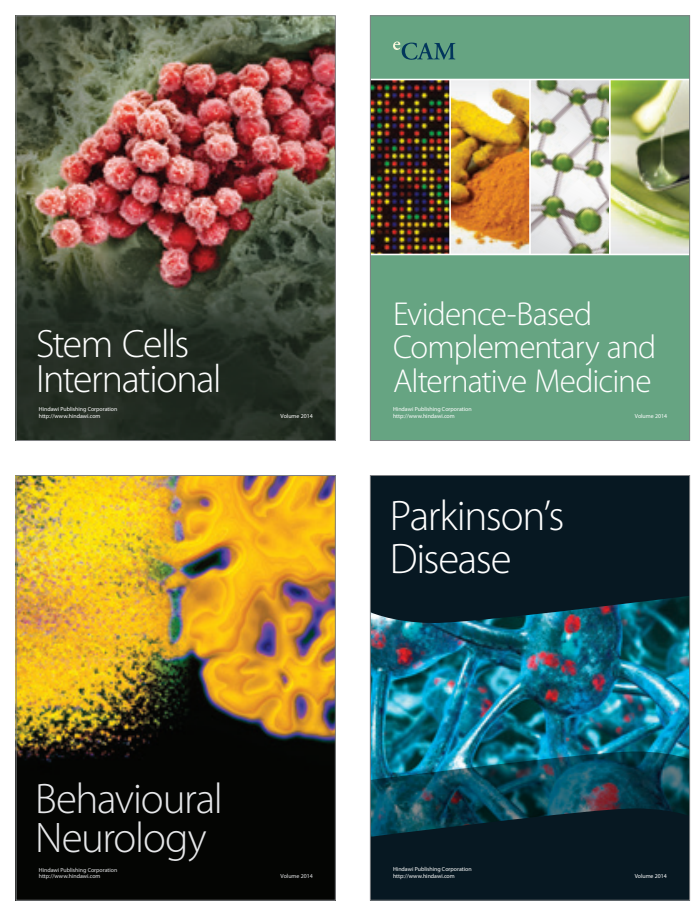

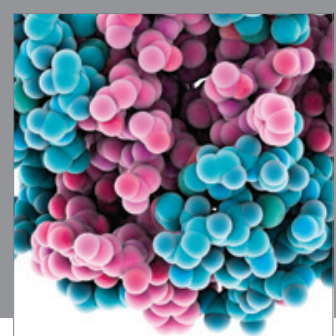

Journal of
Diabetes Research

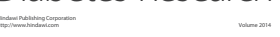

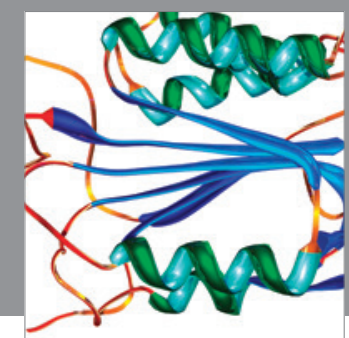

Disease Markers
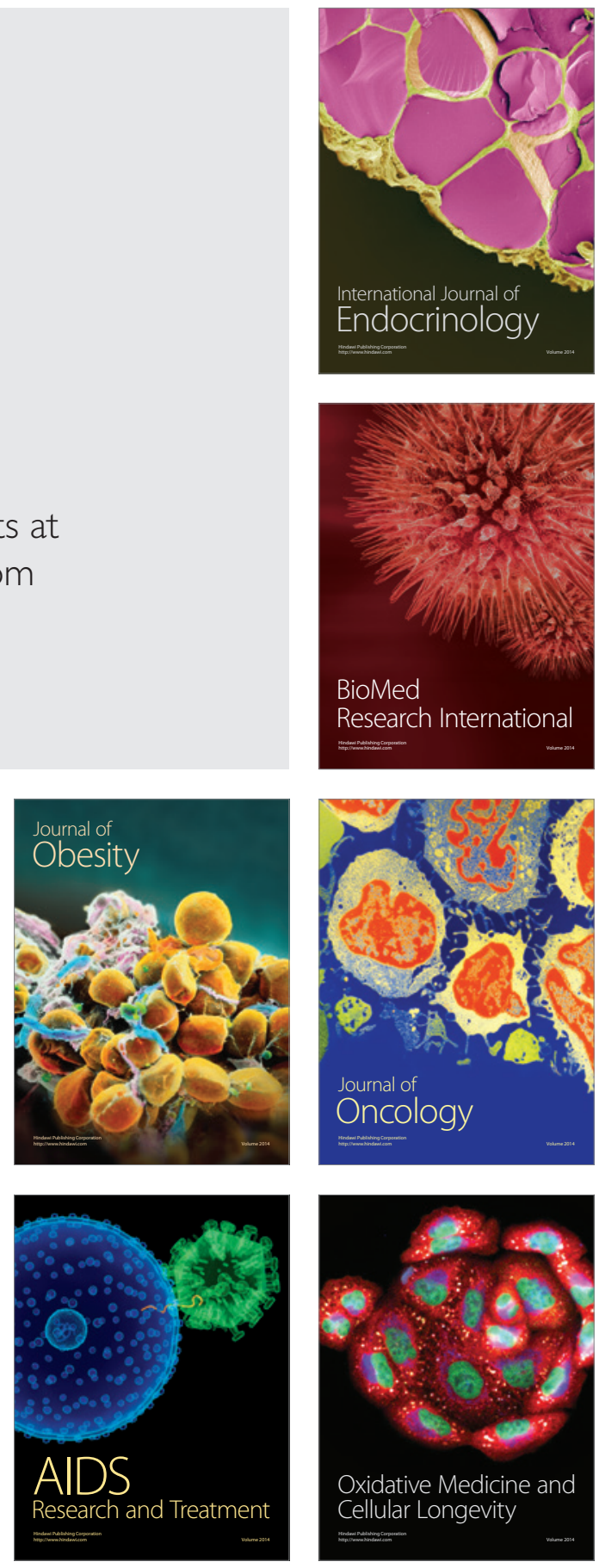